Como citar este artículo en APA: Haya, V. (2019). La Anunciación del Ángel en arameo como constelación de sentido. Cuestiones Teológicas, 46 (106), 223-242. doi: http://doi.org/10.18566/cueteo.v46n106.a02

Fecha de recepción: 12 de agosto de 2019 Fecha de aceptación: 29 de octubre de 2019

\title{
LA ANUNCIACIÓN DEL ÁNGEL EN ARAMEO COMO CONSTELACIÓN DE SENTIDO
}

The Annunciation to the Blessed Virgin Mary in Aramaic as Constellation of Meaning A anunciação do anjo em arameu como constelação de sentido

\author{
Vicente Haya ${ }^{\mathrm{I}}$
}

1 Doctor en Filosofía por la Universidad de Sevilla, España. Licenciado en Historia por la Universidad de Granada, España. Profesor Ayudante Doctor en la Facultad de Filología de la Universidad de Sevilla. Correo electrónico: vicente.haya@gmail.com 


\section{Resumen}

En este artículo se comenta el pasaje del Evangelio de Lucas 1,26-1,38 (la Anunciación del Ángel a María), analizándolo, palabra por palabra, a partir del texto siriaco de la Pëshitttâ', según transcripción del Codex Khabouris realizada por Stephen P. Silver, vocalizada al modo de las iglesias cristianas orientales caldea y asiria.

Palabras clave: Anunciación; Peshitta; Gabriel; María; Ángel; Iglesias orientales; Khabouris; Caldeos; Asirios; Arameo; Siríaco.

\section{Abstract}

The article includes a comment on the passage of the Gospel of Luke 1, 26-38 (The Annunciation to the Blessed Virgin Mary), analyzing it verbatim based on the Syriac text of Peshitta with the transcription of the Khabouris Codex by Stephen P. Silver and the writing style of the Chaldean and Assyrian Churches. Key Words: Annunciation; Peshitta; Gabriel; Mary; Angel; Church of the East; Khabouris Codex; Chaldean; Assyrian; Aramaic; Syriac.

\section{Resumo}

O artigo comenta o extrato do Evangelho segundo Lucas 1,26-1,38 (A anunciação do Anjo a Maria), para isso analisa palavra por palavra a partir do texto siríaco da Pëshîttâ', conforme a transcrição do Codex Khabouris feita por Stephen P. Silver e vocalizada ao modo das igrejas cristãs caldeias e assírias. Palavras chave: Anunciação; Peshitta; Gabriel; Maria; Anjo; Igrejas orientáis; Khabouris; Caldeus; Assírios; Arameu; Siríaco.

\section{Introducción}

Hacia fines del siglo II Taciano compone en arameo una vida de Jesús denominada Diatessaron, unánimemente utilizada y citada en sus textos por los Padres de la Iglesia de habla siriaca hasta mediados del siglo V. Desde 
los años 615-616 tenemos una versión aramea de la Biblia completa, editada en Egipto por Tomás de Heraclea, basada en un texto anterior preparado por Filoxeno de Mabug y revisada más tarde por el corepíscopo Policarpo, que se cita corrientemente como Pëshîttâ', y que es la que usan hasta hoy las Iglesias cristianas orientales de rito siriaco, así como las que están en comunión con la Iglesia de Roma.

En este artículo nos embarcaremos en la lectura del pasaje de la Anunciación del Ángel (Lucas 1:26-38) con la esperanza de que una lengua muy próxima -no idéntica- a la que empleó Jesús en sus predicaciones (y en su vida diaria) despierte en nosotros una nueva sensibilidad para entender mejor su mensaje.

\section{Primera parte: texto siriaco con traducción razonada}

En la Pëshîțâ' leemos:

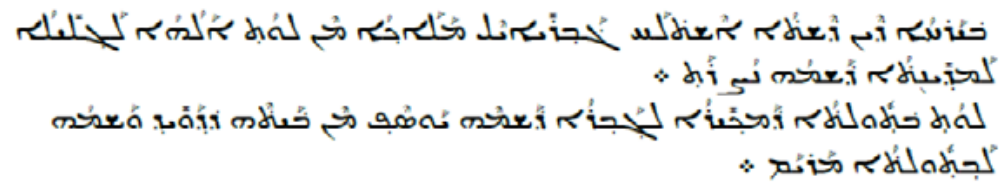

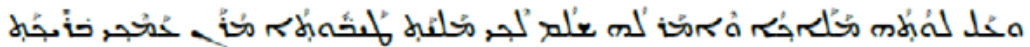

$\therefore$ -

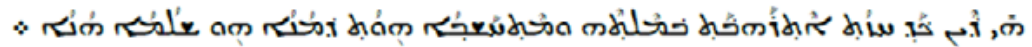

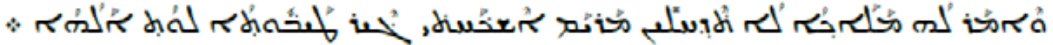

• Rُ

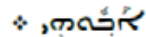

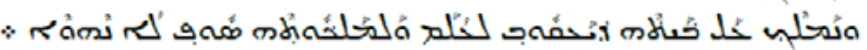

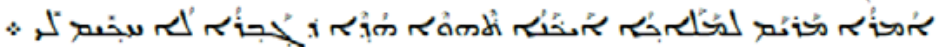

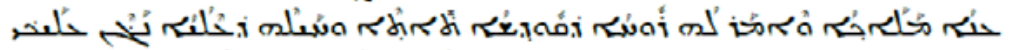

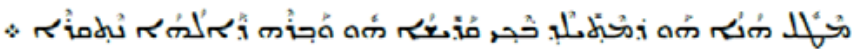

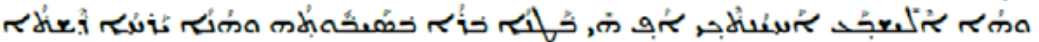

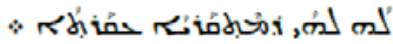

*

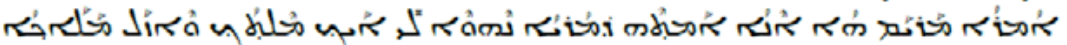

$\circ$ mमेंal से 
Lucas 1:26 - Bëyarhâ' dên [Pero en el mes] deshtâ' [que (es) el sexto] 'eshtëlah [fue enviado] Gabrî̀'yel [Gabriel] mal'la 'k̂â' [el enviado] men [de, desde] lëwât [el lado de, la presencia de] 'Alllâhâ' [Dios], la Ǵlîlâ' [a Galilea] lamëdîntâ' [a la ciudad] dashmâh [de nombre de ella] Nâșrat [Nazaret]. En castellano plano: «Entonces, en el mes sexto, fue enviado Gabriel, el Mensajero, desde la presencia de Dios, a Galilea, a la ciudad de nombre Nazaret». Comentario: más allá de los conceptos a los que responden las palabras usadas y de la traducción dada a estos conceptos, debemos poner en funcionamiento nuestra sensibilidad para percibir qué se nos está transmitiendo. ¿̨or qué Gabriel tiene ese nombre, o, mejor dicho, por qué es Gabriel el ángel que ha sido enviado y no cualquier otro? ¿Por qué "ángel" se dice así en arameo, recurriendo a la raíz trilítera L-'-K; o, lo que es lo mismo: qué es un ángel? ¿Por qué a Dios se lo llama así ( ' $A l \cdot l a \hat{h} h a ̂$ ')? ¿Tiene Dios más nombres en arameo? Todas estas son cuestiones que, de una forma o de otra, también están en el texto, y que por eso también las está escuchando -consciente o inconscientemente- el oyente arameo. No son, pues, añadidos filológicos sino cuestiones que forman parte de la Revelación que nos está llegando y que debemos de desvelar en la exégesis que hagamos del pasaje.

Lucas 1:27 - lëwât [a la presencia de] bëtûltâ' [la virgen] damëkîrấ [que (fue) dada en matrimonio] lëgabrấ ' [al hombre] dashmeh [de nombre de él] Yawsep [José] men [de, desde] bayteh [la casa de él] dëDawîl [de David] washmâh [y su nombre] labeẹtûltâ' [a la virgen] Maryam [María]. En castellano plano: «a la presencia de la virgen que fue desposada con un varón de nombre José, de la Casa de David. Y el nombre de la virgen era María». Comentario: lo más interesante de este versículo son los conceptos de 1) bëtûltâ', que no necesariamente siempre significa "virgen"; por ejemplo, en hebreo babilónico, significa mujer que, a pesar de no serlo, no ha llegado a parir. y 2) "desposada" [mëkîirâ]: tercera persona del singular del participio pasivo de la raíz verbal M-K-R; lo traduciríamos "desposada". Pero, literalmente, sería el verbo "adquirir a un precio"; o sea, que, en su más cruda literalidad, este participio pasivo sería "vendida". Las lenguas son cristalizaciones de los mundos que las originaron, y la actitud patriarcal acaba evidenciada en ellas.

Lucas 1:28 - wëal [y entró] lëwâtâh [hacia ella, al lado de ella, a la presencia de ella] mal lla ' $k \hat{a}$ ' [el enviado, el mensajero] we'mmar [y dijo] lâh [a ella] shëlâm leky [shëlâm a ti] malyat [inundada de, empapada de] taybûtấ 
[gracia, amabilidad, dulzura, agradecimiento...] Mâran [nuestro Señor] 'ammeky [contigo] bërikkat [poseedora de bërkâ'] bëneshe' [entre las mujeres]. En castellano plano, con algún concepto arameo pendiente de explicar: "Y entró hacia ella el mensajero. Y dijo a ella: shëlam, tú que estás a rebosar de gracias, Nuestro Señor está contigo, poseedora de berkấ entre las mujeres». Este versículo es objeto de una exégesis pormenorizada en el apartado "La necesidad de abismarnos".

Lucas 1:29 - Hî dên [Pero ella] kad [cuando, mientras] hëçât [vió] 'etrahbat [se atemorizó, tembló, se agitó, echó a correr de miedo] bëmelëteh [con la palabra de él] wëmethashb $\hat{a}^{\prime}-h w a \hat{t} \underline{t}$ [y estuvo calculando, y estuvo planeando, y estuvo ponderando, y estuvo pensando] dëmânâ ${ }^{\prime}$ [que qué] hû [él = es] shëlâmâ' [el saludo] hânâ' [este]. En castellano plano: «Pero ella, cuando lo vió, se atemorizó con la palabra de él y se puso a meditar qué significaba este saludo».

Lucas 1:30 - We'mmar [y dijo] lâh [a ella] mal·la'k $k a^{\prime}$ [el enviado, el mensajero] lâ' [no] tedhëlin [temas] Maryam [María] 'eshkahty gêr [porque has encontrado] taybût $\hat{a}$ ' [gracia] lëwât [en presencia, junto a] 'Alllâhâ' [Dios]. En castellano plano: «Y dijo a ella el Mensajero: "No temas, María, porque has encontrado gracia en presencia de Dios"». Comentario: Vuelve a salir la palabra țaybûtấ'. El Mensajero repite palabras como si también él estuviera nervioso: "Eres la llena de gracia...", "has en contrado gracia ante Dios", son frases que sobreabundan en lo mismo. La razón que el ángel da a María para no tener miedo es la gracia de que ha sido objeto. La gracia desarticula el miedo: "No hay razón para que tengas miedo, porque tienes gracia". El verbo arameo "encontrar" es el mismo verbo "ser capaz". Haber encontrado gracia es haber conseguido gracia. Dios la otorga, pero la otorga por algo que hacemos o no hacemos.

Lucas 1:31 - Hầ' gêr [Pues he aquí que...] tëqablin [recibirás] batnấ [embarazo, feto] wëti'ldîn [y engendrarás] bërấ' [criatura] wëteqrên [y llamarás, e invocarás, e invitarás, y leerás, y recitarás, y gritarás, y proclamarás] shëmeh [el nombre de él] Yesh $\hat{u}^{\circ}$ [Jesús]. En castellano plano: "Pues he aquí que recibirás embarazo y engendrarás criatura, y le llamarás "Jesús"». Comentario: hemos visto que en el océano de la mera literalidad se mueven corrientes internas que apenas han conseguido sobrevivir a la 
traducción. Lo primero que nos llama la atención del texto original de Luc 1:31 es que el Mensajero no diga a María "y será llamado Jesús", como si ella quedara al margen, sino que construye una forma verbal en la que María tiene todo el protagonismo: es María la que le llamará "Jesús". Y no solo "le llamará. En esto tenemos que comprender que, en arameo, ninguna palabra significa una sola cosa: también será ella la que "convocará" el nombre de Jesús, la que "proclamará" el nombre de Jesús. Se hace, por tanto, necesario y urgente, para comprender la hondura del mensaje del ángel, viajar al fondo de las raíces de la palabra "Jesús". Yeshû̀ es la forma abreviada de Y'hôshûa (que aparece ya en Éxodo 17:9 s, Num. 11:28, etc), que a su vez es la contracción de Y'hôvâh yâsha ${ }^{\circ}$. La raíz verbal Y-SH- ${ }^{\circ}$ en su significado-raíz es "estar abierto, ancho, libre", y, por extensión, "abrir, liberar, dar la victoria, dar prosperidad, poner a salvo". Jesús $\left(\right.$ Yeshû $^{\circ}=$ Ychôshûa $^{\circ}=$ Y'hôvâh yâsha ${ }^{\circ}$ ) literalmente, tendría múltiples significados: "Dios libera, Dios da la victoria, Dios protege, Dios da prosperidad, Dios abre (nuestros horizontes, nuestra vida).

Lucas 1:32 - Hânâ' [éste] nehwe' [será] rab [grande] wabreh [y la criatura de él] dëEllâyâ' [del Altísimo] nețqëre'[será llamado, será invocado, será invitado, será leído, será recitado, será gritado, será proclamado] wënettel [y dará] leh [a él] Mâryâ' [El Señor] 'Al-lâhâ' [Dios] kûrsëyeh [el trono de él] dëDawî́ [de David] 'abûhy [el padre de él]. En castellano plano: «Éste llegará a ser grande. Y será llamado "la criatura del Altísimo". Y el Señor-Dios le dará el trono de David, su padre».

Lucas 1:33 - Wënamlek [y reinará] ${ }^{\circ}$ al [sobre] bayteh [la casa de él] dëYa ${ }^{\circ} q \hat{u} \underline{b}$ [de Jacob] lë âlam [por siempre] walmalkûteh [y su reino] sûfo [un límite] lâ' [no] nehwe' [habrá]. En castellano plano: «y reinará sobre la casa de Jacob por siempre, y su reino no tendrá límite».

Lucas 1:34 - 'Âmrâ' [decidora, diciente, es la que dice] Maryam [María] lëmal·la'kâa' [al mensajero] 'aykannâ' [cómo] tehwe' [será] hâde' [esta (cosa)] dëgabrấ' [que hombre] lâ' [no] hëkîm [conocido] lî [para mí]. En castellano plano: María es la que dice al Mensajero: «¿Cómo será esta cosa? Que el varón no es algo que yo conozca». Comentario: no es exactamente igual traducir "María dice" que "María es la que dice". Asimismo, no es igual traducir "no he conocido varón" que "el varón no 
es algo conocido por mí". Son matices que hay que respetar. En ambos casos, María pierde pasividad, gana protagonismo: "La que dice (lo que sea) es María”, "el varón es algo conocido (o no) por ella”... A pesar del modo elegante de María de explicar que no ha tenido relaciones sexuales, mediante el verbo "conocer", en este contexto la raíz verbal de "varón" cobra toda su fuerza, fuerza viril. Pero no deja de ser fascinante que sea precisamente a un ángel llamado Gabrî’yel a quien le esté diciendo que aún no ha conocido $\dot{g} a \underline{b} r a ̂$ '. Algún aspecto de la vulnerabilidad de María queda claramente de manifiesto.

Lucas 1:35 - ${ }^{\circ} \ddot{E} n \hat{a}^{\prime}$ [contestó] mal $\cdot l a{ }^{\prime} k \hat{a}^{\prime}$ [el enviado, el mensajero] we 'mmar [y dijo] lâh [a ella] rûhâ' [el espíritu, el viento, el soplo, el aliento, el olor] dëqûdshâ' [de lo sagrado] ti 'te' [venga, viene, vendrá]

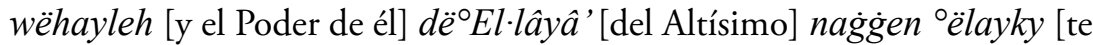
envolverá protegiéndote, extenderá su protección sobre ti] mettul [por la causa de] hânâ' [este] haw [ese] dëmetîled [que será engendrado] beky [en ti] qaddîshâ' [santo] hû [él = es] wabreh [y la criatura de él] da 'lâhâ' [de Dios] netqëre’ [será llamado]. En castellano plano: "Contestó el Mensajero, y dijo a ella: "la R̂hhâ' dëqûdshâa' vendrá, y el Poder de Él, del Altísimo, te cubrirá. Por causa de éste, ése que será engendrado en ti es santo. Será llamado la criatura de Dios" ». Comentario: El Nombre divino "El Altísimo", que ya se citó en el versículo anterior, vuelve aquí a resonar, y, en este versículo, por dos veces se menciona la raíz Q-D-SH, relativa a la insondabilidad de lo sagrado. Todo ello crea una envoltura de misterio, que queda aún más patente cuando la propia raíz verbal "envolver" (G-N-N) se abre paso entre las palabras del Ángel.

Lucas 1:36 - Wëhâ' [Y he aquí que] 'Elîsh $\underline{b} a^{\circ}$ [Isabel] 'ahyânteky [tu pariente] ' $\hat{a} f$ [también] $h \hat{\imath}$ [ella = está] batnâ' [embarazada de] bërâ' [criatura] bësaybûtâh [en su edad, en su ancianidad] wëhânâ' [y este] yarhâ' [mes] deshtâ' [que (es) el sexto] lâh [para ella] lëhây [para esa] dëmetqaryấ [que es llamada] ${ }^{\circ} \ddot{e q a r t} \hat{a}^{\prime}$ [la estéril]. En castellano plano: "Y he aquí que Isabel, tu pariente, también ella está embarazada... Una criatura a su edad... Y este mes, que es el sexto para ella, para esa que es llamada "la estéril"...».

Lucas 1:37 - Mettul [por causa de] dëlâ’[que no] `ëtel [(es) difícil] la 'lâhâ' [para Dios] meddem [algo, cosa]. En castellano plano: «Porque no es difícil para Dios ninguna cosa». 
Lucas 1:38 - 'âmrâ' [decidora, diciente, es la que dice] Maryam [María] $h \hat{a}$ ' [he aquí que] 'ennâ' [yo = soy] 'amteh [la sierva de él] dëMâryâa' [del Señor] nehwe' [será] lî [para mí] 'ayk [según] melëtâk [la palabra tuya] we'ççal [y se fue] mal $\cdot l a{ }^{\prime} k \hat{a}^{\prime}$ [el enviado, el mensajero] men lëwâtâh [de la presencia de ella, de junto a ella, de ella]. En castellano plano: María es la que dice: "'He aquí que soy la sierva de Él, del Señor. Sea para mí según tu palabra”. Y se marchó el Mensajero de su presencia». Comentario: así concluye el pasaje de María y el Ángel. Han salido nuevas cosas que llaman nuestra atención, y que merecen ser comentadas. Pero la que destaca entre todas es ese nehwe' lî 'ayk melëtâk ("será para mí según tu palabra") es una expresión llena de fuerza. María, con estas palabras, está contribuyendo a que ocurra lo anunciado. Lejos de la pasividad que a veces algunos le atribuyen, una María que simplemente recibe la noticia de un hecho que va a producirse y que acepta resignada la voluntad divina, mediante la frase nehwe'lî 'ayk melëtâk está demostrando que es capaz de proyectar su voluntad hacia el Cielo: “¡Va a ser así como has dicho!”.

\section{Segunda parte: comentario}

\section{La necesidad de orientarnos}

El encuentro de María con el Ángel, narrado en arameo, es el cielo que ahora se despliega ante nuestra mirada. En este cielo se distinguen con claridad constelaciones de estrellas que nos sirven para no estar perdidos en nuestro caminar nocturno por el desierto. Queremos, ante todo, que la Revelación nos sirva como carta de navegación; queremos entender dónde estamos y hacia dónde vamos.

En este texto, en arameo, descubrimos tres constelaciones de sentido en las palabras que se usan, y, gracias a ellas, creemos entender mejor lo que la Revelación nos viene a comunicar. 


\subsection{Primera constelación: los nombres}

En primer lugar, observamos que en tan solo trece versículos aparecen ya trece nombres propios de persona (eliminando las repeticiones, tenemos: Gabriel, Galilea, Nazaret, José, David, María, Jesús, Jacob, Isabel, Judea). Hay otros nombres que, no siendo nombres propios sino sustantivos en forma enfática -con artículo determinado-, se están usando como tales: El Ángel, La Virgen, El Espíritu de Santidad, y, por supuesto, El Dios ('Al-lâhâ'). Ya vamos por 23 nombres. Sumémosle ahora los Nombres de Dios que se usan en el texto: al ya mencionado 'Al·lâhâ' ("El Dios", 4 veces), hay que añadir "El Más Alto" ( ${ }^{\circ} E l \cdot l a ̂ y \hat{a}^{\prime}, 2$ veces) y "El Señor" (Mârâ', Mâryâ'; 3 veces); y suman 28 nombres propios. No nos detengamos todavía, que quedan los nombres de Jesús: al niño que va a nacer se le llamará "Jesús", "Hijo del Altísimo" (bërâ' dëEl-lâyâ'), "Hijo de Dios" (bërâ'd'Al-lâhâ), "El santo" (Qaddîshâ'). Estamos en 32 nombres propios. Esta raíz verbal: "llamar" (Q-R-') $)^{2}$, aparece en cinco ocasiones en estos trece versículos; las cuatro aplicadas a Jesús que acabamos de citar y una referida a Isabel... En resumen, tenemos nombres propios, nombres comunes usados como nombres propios, nombres de Dios, nombres de Jesús, raíces verbales que aluden al modo de llamar a la gente... ¿Y qué más? ¡La palabra nombre! Shëmâ' aparece cuatro veces en el texto: "una ciudad de nombre Nazaret", "un varón de nombre José", "el nombre de la virgen era María", "el nombre por el que se le llamará será Jesús”.

¿Qué podemos deducir de todo esto? ¿Para qué nos sirve esta minuciosa contabilidad, cuya riqueza de matices, por cierto, se pierde en las traducciones? Para un primer acercamiento al Texto. Sea lo que sea este firmamento estrellado que ahora contemplamos (Lucas 1:26-1:39) hay estrellas que pertenecen a una misma constelación, y las vemos enseguida: la constelación de los Nombres. Es nuestra primera referencia en un cielo cuajado de estrellas. En Lucas 1:26-1:39 estamos ante una presentación en toda regla y a varios niveles: un Ángel que se presenta a María y que le

2 La misma raíz en árabe da origen a la palabra "Corán”: la "llamada”. 
presenta a Jesús, y un Evangelista que nos presenta a los personajes de los que va a hablar. No son gente en abstracto ni pertenecen a un momento indeterminado del tiempo: hay una genealogía en la que tienen sus raíces afirmadas, hay una Historia Sagrada de la que son herederos, y hay una geografía donde ubicarlos: la región de Galilea, la casa de Jacob, el trono de David...

Ubicarlos, ubicarnos; esta es la primera función de esta constelación de palabras formada por Nombres. «En el principio era la Palabra», ya lo sabemos por el Evangelio de Juan. Y, de hecho, la palabra aramea "palabra" (melt $\hat{a}$ ) va a formar también parte de esta constelación, y la encontramos en el justo centro de la misma, en dos versículos definitivos y fulminantes: el que nos habla de una María que, al ver al Ángel, tembló de miedo con su Palabra (hî dēn kad hẹzzât 'etrahbat bëmelțeh), y el de una María que, después del encuentro, responde que se haga en ella según la Palabra que ha pronunciado el Ángel (nehwe'lî 'ayk meltâk $\underline{\text { ) }}$.

Nunca, en arameo, una palabra es tan sólo una palabra. El término "palabra" en arameo es también la "cosa" misma. No estamos en una tradición en que la palabra pueda sostener un "concepto", como en el mundo griego. La palabra tiene una eficacia en sí misma y transforma las cosas a su paso. De ahí la importancia que tienen los nombres de las cosas, los nombres de las personas. Si Jesús va a ser llamado "Jesús" es porque su nombre dice lo que será de verdad (Jehoshua: Yehôvâh yâsh $\hat{a}^{\circ}$ : "Dios libera, Dios da la victoria, Dios salva"). Y el Poder de Dios cambia los nombres de las cosas, cuando estos no son verdaderos: "estéril" es un nombre que no responde a lo que es Isabel y Dios interviene para hacérnoslo evidente.

\subsection{Segunda constelación: la concepción}

A la Constelación de los Nombres, que fue la que primero distinguimos en el firmamento del texto, se le suma ahora otra constelación de términos en torno a la idea de la Concepción. Es (y así se ha presentado siempre) el tema central del encuentro entre el Ángel y María, por eso no nos sorprende verla ahí, iluminando nuestro cielo nocturno. En pocas palabras, el ángel Gabriel se le aparece a la virgen María, antes de que haya convivido y, por tanto, 
consumado su unión con José, y le anuncia que va a quedar embarazada del Espíritu Santo, y que va a dar a luz a una criatura, a la que llamará Jesús.

Sin embargo, en arameo, el pasaje va a presentar una riqueza de matices digna de ser mostrada:

1. se nos habla de una virgen (bëtûla $\hat{a}^{\prime}$, bët $\left.\underline{u} l t \hat{a}{ }^{\prime}\right)$; esto es correcto. Aunque no está por demás añadir que en el aramaico de los judíos de Babilonia tendría el matiz de "la que no ha parido".

2. una mujer desposada con un varón, dicen algunas traducciones al uso. A nosotros nos parece más adecuada la expresión "prometida". En realidad, ambas traducciones estarían maquillando la cruda textualidad de una sociedad patriarcal: damkîrâ' (partícula $\mathrm{d}+$ participio pasivo, peal, de la raíz M-K-R) significa literalmente "que ha sido vendida".

3. una mujer prometida -o por la que ya ha pagado una dote- un hombre ( $\dot{g} a \underline{b} r a ̂)$, llamado José, ante la que se presenta un Ángel cuyo nombre, en sí mismo, es ya un desasosiego para una mujer que no ha tenido aún relaciones sexuales: el ángel se llama Gabriel (Gabrî́yel, de la misma raíz de "hombre", gabrâ: G-B-R). En esta raíz trilítera G-B-R, tan relacionada con la virilidad, hay un sabor intrínseco de "forzar, más allá de las resistencias" que ciertamente puede resultar incómodo a algunas mentalidades.

4. Y hemos dicho que, ante esta virgen, se presenta el Ángel. El tema es más complejo en su significado textual. Si vamos a la mayoría de las traducciones al uso del versículo de Lucas 1:28 leemos:

(BLPH) El ángel entró en el lugar donde estaba María y le dijo:

(BTX3) Y entrando en donde ella estaba, dijo:

(DHH) El ángel entró en el lugar donde ella estaba, y le dijo:

(EUNSA) Y entró donde ella estaba y le dijo:

(NT Peshitta-ES) Entrando el ángel adonde ella estaba, le dijo:

(RCB) Y entrando el ángel en donde ella estaba, dijo:

(SRV) Y entrando el ángel á donde estaba, dijo:

(LBLA) Y entrando el ángel, le dijo: 
(NT Besson) Entrando hasta ella el ángel, dijo:

(TNM) Y cuando entró delante de ella, dijo:

(KADOSH) Acercándose a ella, el malaj dijo:

(NVI) El ángel se acercó a ella y le dijo:

(NT BAD) Gabriel se le apareció y le dijo:

(NTV) Gabriel se le apareció y dijo:

5. La mayoría de los traductores (desde el griego o el latín) parecen tener claro que el Ángel entra en un lugar en el que María está, o que se le acerca, o que se le aparece. En arameo, la expresión que se usa es "entra a ella": wë al lëwâtâh mal la 'k $\hat{a}^{\prime}$ (y entró a ella el ángel). El diccionario explicita más aún el uso de la partícula lëwât con esta raíz verbal:

○-L-L: entrar (arameo común): 1(a) normalmente rige la partícula l- (a, para): (a.1) "entrar $a$ un lugar", (a.2.) figuradamente: "entrar en una situación o condición".

2 Con las partículas ${ }^{\circ} \mathrm{l}$ (sobre), ${ }^{\circ} \mathrm{m}$ (con), lëwat , en arameo galilaico, arameo targúmico palestinense y siriaco sería "tener relaciones sexuales con". 3 "Ser iniciado en misterios", "penetrar en la cámara nupcial”.

Cuando, ya en Lucas 1:38, el Ángel se va, el texto mantiene un estricto paralelismo con el modo en que comenzó el pasaje. Los traductores que entienden que el Ángel ha estado ante ella versionan:

(EUNSA) Y el ángel se retiró de su presencia.

(LBLA) Y el ángel se fue de su presencia.

(NT Peshitta-ES) Y el ángel se marchó de su presencia.

(NT BAD) Y el ángel desapareció.

Pero, al menos en arameo, se está diciendo we 'ççal mal·la'k̂â' men lëwâtâh (y el ángel se fue de ella).

Por tanto: una virgen, prometida a un varón, un Ángel, que es el que rompe las resistencias, la entrada del Ángel, la salida del Ángel... ¿Y qué más? ¿Qué más elementos descubrimos en esta constelación de términos? Los que cabía esperar y algunos que nos sorprenden agazapados bajo las raíces del idioma que se usa: a María se le dice «concebirás (tëqablîn baṭnâ') y 
engendrarás (wëti ldîn) criatura (bërâ')", y se la llama "la llena de gracia” (malyat taybûtấ), que, en arameo literalmente sería "la que experimenta una inundación” (mël·le', mël·le’â) de gracia. Y, por otra parte, se nos habla de otra mujer a la que antes llamaban estéril ( $\left.{ }^{\circ} \ddot{q} q a r t a ̂\right)^{\prime}$ y que, sin embargo, ya está en el sexto (shittâ', 'eshtâ') mes de embarazo. Incluso el modo de decir que Isabel está de seis meses tiene relación con la fecundidad; el texto dice en arameo: bëyarhhâ' deshtâ' ("en el mes en que se riega") de la raíz verbal SH-T-', “ser irrigado”. Es la segunda vez que sale este mes en este pasaje (1:26, 1:34). No puede ser casualidad que signifique lo que significa, y que aluda a la fertilidad.

Si mientras contemplábamos la constelación de los Nombres susurrábamos en nuestro corazón el versículo del Evangelio de Juan, «En el principio fue la Palabra» (Juan 1:1), ante esta nueva constelación -articulada en torno a la idea de la concepción- nuestro corazón no cesa de repetir el versículo: «Y la Palabra se hizo carne» (Juan 1:14).

\subsection{Tercera constelación: el poder}

Ya hemos comprendido la importancia que tienen para orientarnos en nuestro caminar dos constelaciones de sentido. Ambas eran fáciles de descubrir en el firmamento estrellado. La Constelación de los Nombres y la Constelación de la Fecundidad estaban ahí delante, a ojos vista. Pero también hay otras estrellas que forman una constelación más amplia y, por eso mismo, requiere un particular adiestramiento saber verla en nuestro firmamento. Y sin ella el texto no se entiende en todas sus dimensiones.

Veamos el mismo pasaje de Lucas 1:26-1:39 en la traducción al uso de la Biblia de Jerusalén, pero señalando las palabras cuyas raíces en arameo van a formar esta tercera constelación que nos guíe en nuestro caminar:

Y entrando, le dijo ('-M-R): «Alégrate, llena de gracia, el Señor ('-M-R) está contigo.» Ella se conturbó (R-H-B) por estas palabras (M-L-'), y discurría qué significaría aquel saludo. El ángel le dijo ('-M-R): «No temas (D-H-L), María, porque has hallado (SH-K-H) gracia delante de Dios ('-L-H); vas a concebir en el seno y vas a dar a luz un hijo, a quien pondrás por nombre Jesús. Él será grande (R-B) y será llamado Hijo del Altísimo $\left({ }^{\circ}-\mathrm{L}-{ }^{\prime}\right)$, y el Señor 
('-M-R) Dios ('-L-H) le dará el trono (K-R-S) de David, su padre; reinará (M-L-K) sobre la casa de Jacob por los siglos $\left({ }^{\circ}-\mathrm{L}-\mathrm{M}\right)$ y su reino (M-L-K) no tendrá fin.» María respondió ('-M-R) al ángel: «¿Cómo será esto, puesto que no conozco varón (G-B-R)?». El ángel le respondió ('-M-R): «El Espíritu Santo vendrá sobre ti y el poder (H-Y-L) del Altísimo ( $\left.{ }^{\circ}-\mathrm{L}-{ }^{-}\right)$te cubrirá con su sombra; por eso el que ha de nacer será santo y será llamado Hijo de Dios ('-L-H). Mira, también Isabel, tu pariente, ha concebido un hijo en su vejez, y este es ya el sexto mes de aquella que llamaban estéril, porque ninguna cosa es imposible para Dios ('-L-H)»

Estamos, evidentemente, ante la Constelación del Poder. No hace falta explicar la mayoría de estas raíces, porque su sentido sobrevive a las traducciones:

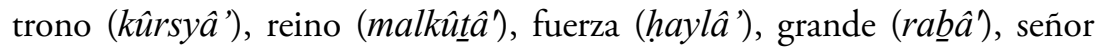
(mâryâ,', mârâ')...; y otros términos arameos más o menos relacionados con el poder ya se han explicado anteriormente, por ejemplo, "hombre" (g்abrâ) o "Gabriel" (Ġabrîyel). Pero hay algunas otras palabras que es importante explicarlas ahora desde su raíz. Habría que empezar por la misma palabra "Dios" ('Al-lâhâ). Ciertamente, no en todas las lenguas, lo divino tiene relación con el Poder; por ejemplo, en las lenguas indoeuropeas alude más bien a la luminosidad. Pero, en las lenguas semíticas, Dios es Poder. Ya sea en ugarítico, acádico, ge'ez, hebreo, árabe, fenicio, arameo o la lengua semítica que queramos, la familia léxica '-L-H se refiere a la fuerza y al poder.

Habría que explicar que, cada vez que se usa el verbo "decir" ('-M-R), se usa la misma raíz de "señor" (mâryâa', mârâ'); porque el que dice algo está expresando su imperio sobre el mundo que lo rodea. De hecho, en la cosmovisión semita Dios crea el universo con su palabra. Por eso, el mismo término "palabra" (mel·lâ", mel·lẹtâ) está en arameo cargado de poder. $\mathrm{O}$, por poner otro ejemplo, cuando se menciona el verbo "encontrar" (SHK-H) en arameo también se está diciendo "ser capaz": "has encontrado gracia a los ojos del Altísimo" significa también que María ha sido capaz de obtener el favor del Poderoso. Si Dios es Poder, el santo es alguien que participa de ese poder.

Y, puesto que en este texto se está hablando del Poder de Dios, la respuesta de María está en esa misma clave. "He aquí la sierva ('amâa', 
'amtấ') del Señor; hágaseme según tu palabra»: María se doblega voluntaria y completamente al Poder de Dios, que es lo que se le ha mostrado.

Ya vemos que hay dos maneras de leer el texto de Lucas 1:26-1:39. En una primera lectura se nos está hablando de unas cosas (concepción, fecundidad...), y, en una segunda lectura, más profunda, el mensaje está en otra clave. A nosotros puede escapársenos o no esta segunda lectura, dependiendo de nuestra finura espiritual o de las traducciones que utilicemos; lo que es seguro es que a María no se le escapó. Porque, al concluir el pasaje de la Anunciación, se va a ver a su prima Isabel... ¿Y qué le dice? ¿Que ha quedado embarazada y que va a parir un niño (a pesar de no haber tenido trato carnal con ningún hombre)? No. No habla de embarazos ni de partos. Lo que le dice es que Dios ha derribado a los poderosos de sus tronos. Es un mensaje bastante insólito para ser una mujer que acaba de recibir la noticia de su embarazo. Y le dice que "el Poderoso", y le llama así, ha dispersado a los soberbios con la fuerza de su brazo, y que ha dado poder a los humildes. Y solo cuando le ha dejado claro a Isabel que de lo que se está hablando es del Poder de Dios, ella misma se suma a la narración y le hace saber a Isabel que este Dios que es Poder ha hecho cosas grandiosas en ella. Es decir, que la ha investido de Poder.

\section{La necesidad de abismarnos}

La constelación de los Nombres, la de la Concepción y la del Poder. Ahora que sabemos, o creemos saber, dónde estamos, estamos agotados; agotados de caminar. Y deseamos detenernos. Detenernos y contemplar ese mismo firmamento estrellado que antes nos sirvió para orientarnos. Ahora no queremos utilizar el Texto para seguir avanzando, para guiarnos por él en nuestro peregrinar. Queremos tan solo ir de estrella en estrella perdiéndonos en ellas.

\subsection{Entre todas las mujeres}

Tan sólo un ejemplo. Miramos allí, a esa parte del cielo nocturno de la Revelación donde lucen ciertas estrellas en torno al versículo de Lucas 1:28: 


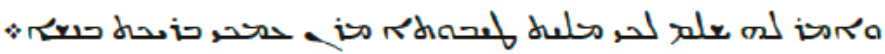

Las traducciones son fotos fijas, momentos petrificados y sin hondura, comparadas con la contemplación directa. Pero vamos a usarlas para acercarnos a lo que contemplamos. En la Biblia de Jerusalén se nos dice que este versículo significa: «le dijo: "Alégrate, llena de gracia, el Señor está contigo", bendita tú entre las mujeres». Y puede ser que eso sea lo que diga; pero todo en arameo sabe mejor, más poético y más hondo. Cada palabra no es sólo lo que significa sino también a lo que apunta y todo aquello que convoca. Veámoslo palabra por palabra (en transcripción vocálica oriental):

We'mmar lâh: «Y dijo [el Ángel] a ella». La raíz '-M-R que en arameo significa claramente "decir" no puede desprenderse por completo del sabor raíz de "imperar, ordenar", que el árabe evidenciará más aún. Como ya dijimos anteriormente, el que dice algo, de alguna forma, está exteriorizando su voluntad, ordenando su medio en la medida que puede o quiere.

Shëlâm lekky: «Shëlâmâa' a/para ti». Sabemos que el saludo en hebreo es Shalôm y que en árabe el equivalente es Salâm; lo que no sabemos es cómo traducir este saludo sin recortar sus significados posibles. "Paz" es una traducción completamente insuficiente. En su fondo último, los derivados de SH-L-M, tanto en arameo como en hebreo, S-L-M en árabe, aludirían a un estar completo en algún sentido: "estar sano" es estar completo, "estar en paz" es estar completo, "estar entregado a Dios" es estar completo. Lo que hace el Ángel no es sólo "un saludo"; es una oración: con ella pedimos a Dios que conceda esa shëlâmâ' a quien va dirigida.

Tras de lo cual, el Ángel continua diciendo a María: malyat taybût $\hat{a}^{\prime}$. En nuestra lengua románica, «Paz a ti, llena de gracia» no puede nunca aspirar a despertar lo que a un arameo-parlante le sugieren los términos de saludo del Ángel. En las lenguas semíticas, las palabras, más allá de sus estrictos significados de uso, buscan incansablemente otras palabras con las que entrelazarse y crear situaciones embriagadoras para todo aquel que sepa paladearlas. Por ejemplo, este shëlâm lekgy no puede entenderse por completo sin conectarlo con una palabra que aparece enseguida: malyat ("llena"). Y, precisamente por eso, el saludo del Ángel en arameo resulta sugerentemente extraño para María, e incluso se nos dice expresamente 
que ella se queda pensando qué podrían significar esas palabras. ${ }^{3}$ Shëlâm... malyat es como si se dijera: "Te deseo que nada te falte..., aunque a ti ya nada te falta". Y luego sigue hablando el Ángel: "Y no te falta nada porque

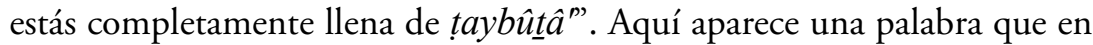
su traducción habitual ("gracia”) queda enteramente desgraciada. "Llena de gracia” es una expresión tan plana, tan vacía de sabor, que ha habido que llenarla con toneladas de teologías. O quizá es al contrario: se ha hecho tanta teología a partir de ella que, al final, ha acabado no significando nada, nada reconocible en nuestra cotidianidad. La taybût $\hat{a}^{\prime}$ es lo contrario: es todo aquello que cualquiera reconoce enseguida por la felicidad de la que emana y que produce en su entorno. El adjetivo, tanto en arameo como en el resto de las lenguas semíticas, puede significar: "satisfactorio, gustoso, útil, recto, hermoso, saludable, benigno, bello, próspero, hábil, alegre, feliz, bueno...”. Ya desde el ugarítico, vemos la raíz T-B asociada con cosas agradables; es decir, con todo aquello que te deja a gusto: "bueno, agradable, dulce". El elemento de la dulzura aparece también en acadio: țâbu ("carne dulce"), y en árabe: tiyâhb es un tipo de dátil especialmente dulce. También la acepción de "hermosura" aparece ya en las primeras páginas de la Biblia: «Y, viendo los hijos de Dios a las hijas de los hombres que eran bellas» (Gen 6:2)... Todo esto, de alguna forma, está relacionado con María, al atribuírsele estar llena, inundada, impregnada de taybûtấ'.

Así es como el Ángel saluda a María diciéndole que está llena de taybûtấ. Antes hablábamos de cómo en este texto son importantes los

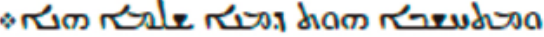

En la Biblia de Jerusalén se nos dice que este versículo, que viene tras el saludo del Ángel, dice: "y discurría (H-SH-B) qué significaría aquel saludo».

No va a ser la única vez que veamos la capacidad de reflexión y análisis de María cruzando el cielo de la infancia de Jesús, como una estrella fugaz:

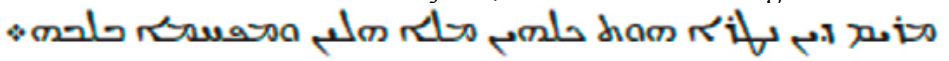

La Biblia de Jerusalén traducirá: «María, por su parte, guardaba (N-T -R) todas estas cosas, y las meditaba (P-H-M) en su corazón». Las revelaciones semitas nos hablan del corazón como lugar de meditación, y, en el caso de los íntimos de Dios, también lugar de encuentro. La función del corazón para un arameo-parlante es la comprensión, y puede ser expresada con varias raíces verbales [H-SH-B (Lucas 5:22), S-K-L (Mateo 13:15), P-Ḥ-M (Lucas 2:19)]. El corazón "cavila”, "entiende", "medita”. 
nombres porque es una presentación. Y decíamos que era una presentación en muchos niveles (el Evangelista nos presenta a unos personajes de la Historia Sagrada, el Ángel se presenta a María y le presenta al que va a ser Jesús...). Hay una presentación más, de la que aún no hemos hablado, porque hasta ahora María solo se conoce hasta donde Dios le ha permitido. Y es ahora cuando el Ángel le descubre, con dos palabras, todo aquello que no sabe de sí misma: "eres malyat taybûtâ"."

Pero resulta que, por virtud del idioma que se está utilizando, malyat taybûtât no es solo un espejo en el que María se ve a través de los ojos del Ángel; sino que también le está anticipando la información que viene a traerle. Porque esa taybûtấ ' de la que María está "llena" se va a convertir en Jesús. De hecho, fijémonos en qué curioso guiño de la lengua sagrada: Jesús va a ser el Mesías (Mëshîhấ'. lit. "ungido con aceite") y uno de los significados de taybût $\underline{a}$ ' es "aceite consagrado".

Acabamos de explicar que el Ángel ha llamado a María "la llena de taybût $\hat{a}^{n}$, y que, signifique lo que signifique, alude a algo de que está dotada una persona que hace que a su lado nos sintamos a gusto. Y, acto seguido, el Ángel le dice que Dios está con ella: mâran ${ }^{\circ} a m m e k y$. El sentido es claro: a Dios le satisface la cercanía de María.

El Ángel podría haber usado cualquiera de los Nombres de Dios o el nombre común, pero emplea el Mârâ', que significa "El Señor, el que da órdenes", de la misma familia que da en árabe Emir ( 'Âmîr), y ya hemos hablado de que todo el texto es una confirmación que se le hace a María de hasta qué punto el Poder de Dios va a estar con ella.

Y, por último, el Ángel acaba diciendo a María: bërîkat bëneshshe', es decir, que si hay una mujer que posea bërâkấ' esa es ella. La frase, que se ha vulgarizado como "bendita entre todas las mujeres" no responde a la plenitud del original. Tener bërâk $k \hat{a}^{\prime}$, más que estar bendecido o ser un bendito, es haber recibido como carisma el poder sanar, el poder vitalizar, el poder reequilibrar las energías alteradas de nuestro mundo. Tener bërâk $\hat{a}^{\prime}$ es tener poder; el poder benéfico de alguien que ejerce su responsabilidad califal en el mundo. De alguien; ni hombre ni mujer. Y, por ello, es realmente 
significativo que no se use la raíz trilítera de "mujer" ( 'anttầ) sino la de "ser humano" ( 'nâshâ').

\section{Referencias}

Aya, A. (2013). El arameo en sus labios. Barcelona, España: Fragmenta.

Brock, S. P. (2006). The Bible in the Syriac Tradition. Piscataway, EE.UU.: Gorgias Press

Dirksen, P. B. (1993). La Peshitta dell'Antico Testamento. Brescia, Italia: FALTA EDITORIAL

Flesher, P. V. M. (ed.) (1998). Targum Studies Volume Two: Targum and Peshitta. Tampa, EE.UU.: University of South Florida

Haya, V. (2019). Descolonizar a Jesucristo. Madrid, España: Akal

Kiraz, G. A. (1996). Comparative Edition of the Syriac Gospels: Aligning the Old Syriac Sinaiticus, Curetonianus, Peshitta and Harklean Versions. Piscataway: Brill, Gorgias Press, 2002 [2nd ed.], 2004 [3rd ed.].

Lamsa, George M. (1933). The Holy Bible from Ancient Eastern Manuscripts. New York: Harper \& Row.

Lindgren, L.J. Dukhrana Biblical Research. http://www.dukhrana.com/

Monferrer, J.P. \& Ferrer Costa, J. (2018) Los Evangelios en arameo. Salamanca, España: Sindéresis

Pikaza, X. \& Haya, V. (2018). Palabras originarias para entender a Jesús. [Comentarios evangélicos desde el griego, el hebreo y el arameo a las principales festividades del año]. Madrid, España: San Pablo

Pinkerton, J. \& R. Kilgour (1920). The New Testament in Syriac. Londrés: British and Foreign Bible Society, Oxford University Press. 
Pusey, Philip E. and G. H. Gwilliam (1901). Tetraevangelium Sanctum iuxta simplicem Syrorum versionem. Londres, Inglaterra: Oxford University Press.

Silver, S.P. The Peshitta New Testament. Disponible en: http://www.dukhrana.com/ khabouris/files/Khabouris\%20Luke.pdf

Weitzman, M. P. (1999). The Syriac Version of the Old Testament: An Introduction. Cambridge, Inglaterra: Cambridge University Press 